\section{Gategory}

Synthesis of

Materials and

Unnatural Products

\section{Key words}

fused ring systems

cyclization

disc-shaped molecules

H. TSUJi,* G. CANTAGREL, Y. UEDA, T. CHEN, L.-J. WAN,* E. NAKAMURA* (THE UNIVERSITY OF TOKYO AND JST-PRESTO, SAITAMA, JAPAN; BEIJING NATIONAL LABORATORY FOR MOLECULAR SCIENCES AND INSTITUTE OF CHEMISTRY, BEIJING, P. R. OF CHINA)

Synthesis of Benzotrifuran and Benzotripyrrole Derivatives and Molecular Orientations on the Surface and in the Solid State

Chem. Asian J. 2013, 8, 2377-2382.

\title{
Facile Access to Heteroaromatic Triphenylene Analogues
}

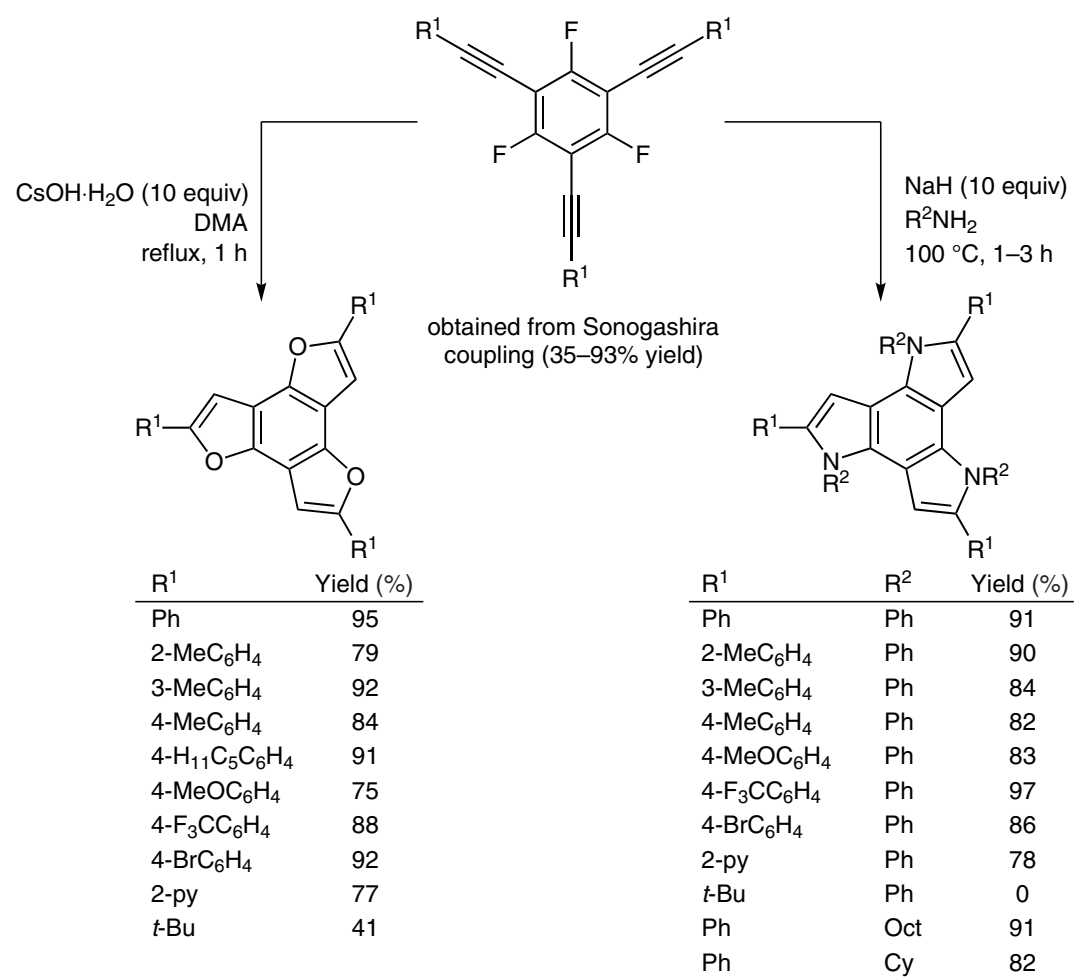

Significance: Planar disc-shaped molecules have attractive properties for applications in materials science, particularly when they exhibit three-fold symmetry. In the present work, the authors demonstrate a versatile approach to the synthesis of benzotrifurans and benzotripyrroles. The $C_{3 h^{-}}$ symmetric target molecules are obtained in a triple cyclization with excellent yields over a wide range of substrates (75-97\%). The authors also study the 2-D molecular arrangement of the phenyl-substituted benzotrifuran via scanning tunneling microscopy and compare it to its 3-D arrangement in the crystalline state.
Comment: The starting 1,3,5-triethynylbenzenes are prepared by Sonogashira coupling with 1,3,5trifluoro-2,4,6-triiodobenzene. Reaction with cesium hydroxide in $\mathrm{N}, \mathrm{N}$-dimethylacetamide (DMA) or with a sodium amide in an amine solvent induces the triple cyclization. For alkynes with tert-butyl substitution, the reaction hardly proceeds beyond the second ring closure. Crystal structures were obtained for four benzotrifurans and one benzotripyrrol, and the authors analyze their emission spectra in the solid state and in solution. 